\title{
Method of obtaining chronic biliary tree access for long- term management of Oriental cholangiohepatitis: Report of a
}

\section{case}

DONALD P. BARTKOWSKI, CAPT, MC, USAF PAUL H. LEVESQUE, MD

RICHARD A. HOEFER, JR, LT COL, MC, USAF

\section{Oriental cholangiohepatitis is}

a chronic and progressive disease characterized by recurrent biliary strictures, primary biliary stone formation, and cholangitis. Past surgical treatment usually included extended choledochotomy, with or without some form of biliary drainage. The following case report illustrates the use of a modified Rouxen-Y choledochojejunostomy to provide internal drainage as well as continuing biliary tree access to manage the complications of this disease. During a 22month follow-up period, the patient was free of jaundice, cholangitis, and symptoms while undergoing percutaneous removal of primary biliary stones and stricture dilation through this jejunal limb on multiple occasions.

Oriental cholangiohepatitis, a chronic, progressive disease, is characterized by recurrent primary hepatobiliary calculi ${ }^{1}$ biliary ductal strictures, ${ }^{2}$ and recurrent episodes of cholangitis. ${ }^{3}$ This disease can progress to chronic pyogenic liver abscess, as well as to hepatic failure. ${ }^{4,5}$ Oriental cholangitis occurs primarily in Asian populations, but it is becoming more frequent in the United States as more people from these populations immigrate to this country.

Surgical procedures used to manage this disorder have included choledochotomy with extended exploration of the bile ducts, transhepatic cholangiolithotomy, and hepatic lobectomy in selected cases. ${ }^{5-10}$ In addition, a drainage procedure usually is performed to allow passage of recurrent biliary calculi and to prevent bile stasis or to provide access to the biliary tree. Such drainage techniques have included chronic T-tube drainage, sphincterplasty, choledochoduodenostomy, and side-to-side or Roux-en-Y choledochojejunostomy. ${ }^{1,5,11-14}$ However, each of these methods have shortcomings in managing the progression and associated complications of Oriental cholangiohepatitis.

The following case illustrates successful use of a modified Roux-en-Y choledochojejunostomy to manage recurrent primary biliary stones and strictures in Oriental cholangiohepatitis.

\section{Report of case}

In September 1983, a healthy, 26-year-old, Korean woman presented to Scott Air Force Base Medical Center, Illinois, with symptomatic cholelithiasis and choledocholithiasis. Based on the radiographic appearance of the biliary tree and the clinical presentation, Oriental cholangiohepatitis was diagnosed.

Exploratory surgery revealed multiple calcium palmitate stones within the gallbladder and the common bile duct (Fig 1). Cholecystectomy, common bile duct exploration, and transduodenal sphincterplasty with Ttube drainage of the common bile duct then were performed.

During the subsequent 19-month period (October 1983April 1985), the T-tube tract was utilized for extraction of retained and recurrent primary intrahepatic biliary calculi on seven occasions. A moderate amount of pain was associated with each T-tube manipulation. The patient experienced one episode of cholangitis, which required hospitalization and a regimen of systemic antibiotics.

In April 1985, a common bile duct exploration with a side-to-side, Roux-en-Y choledochojejunostomy was performed at David Grant USAF Medical Center, California. The procedure was modified to allow the end of the afferent limb to rest in a subcutaneous pocket in the left upper quadrant of the abdominal wall. During the next year, the patient underwent three successful percutaneous extractions of intrahepatic biliary calculi and one dilation of an intrahepatic biliary stricture without difficulty.

During the two-year follow-up periods, the patient has been asymptomatic and has experienced no episodes of cholangitis.

\section{Discussion}

The use of a choledochojejuno-cutaneous fistula to allow balloon dilatation of nonmalignant biliary strictures was described by Hutson and associates ${ }^{15}$ in 1984 . The principles described by these authors were applied to our patient.

Special technical modifications were applied to 


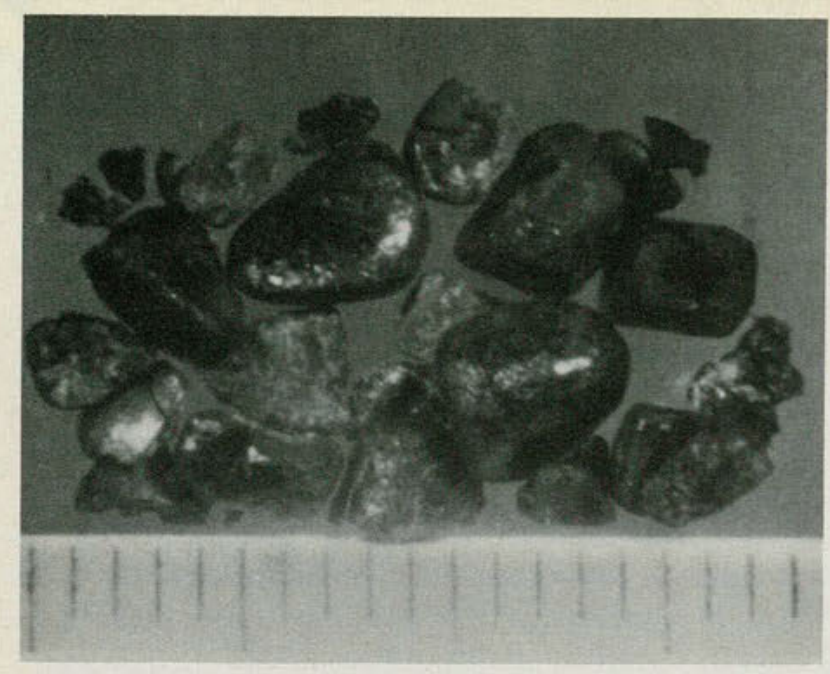

Fig 1. Multiple calcium palmitate stones.

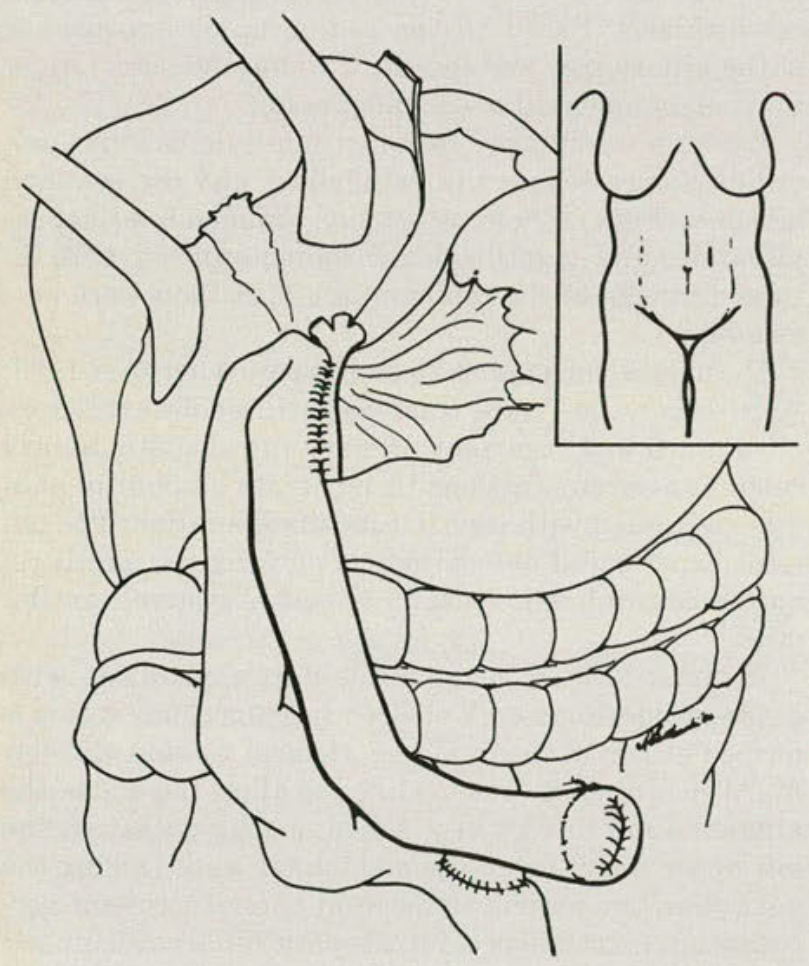

Fig 2. Anatomy of the modified Roux-en-Y choledochojejunostomy, with inset demonstrating location of subcutaneous afferent limb.

the construction of Roux-en-Y choledochojejunostomy in this case. These included a long (approximately $4 \mathrm{~cm}$ ), side-to-side choledochojejunostomy. The afferent limb was oversewn and marked with a wire suture. This long segment then was brought through the left rectus abdominis muscle, anchored to the fascia, and placed in a subcutaneous pocket. The position for the blind end of the afferent limb was chosen to allow an unobstructed view of the biliary system during radiographic evaluation and manipulation (Fig 2). The limb was oversewn rather than left as a cutaneous stoma, primarily because of cosmetic considerations for this young patient.

Percutaneous access to the biliary tree was achieved by fluoroscopically visualizing the end of the afferent limb marked by the wire suture. The jejunal stump then was palpated in its subcutaneous pocket, direct puncture was performed, and a Silastic ${ }^{(\pi 0)}$ sheath was placed into the lumen of the bowel (Fig 3). Correct positioning of the sheath was confirmed by an injection of contrast medium (Fig 4). A floppy guidewire then was passed through the choledochojejunostomy (Fig 5). Once the wire was within the common bile duct, selective catheters could be placed over the wire to extract recurrent biliary calculi (Fig 6) and to dilate intrahepatic biliary strictures (Fig 7).

Fig 3. Location and direct puncture of afferent limb.

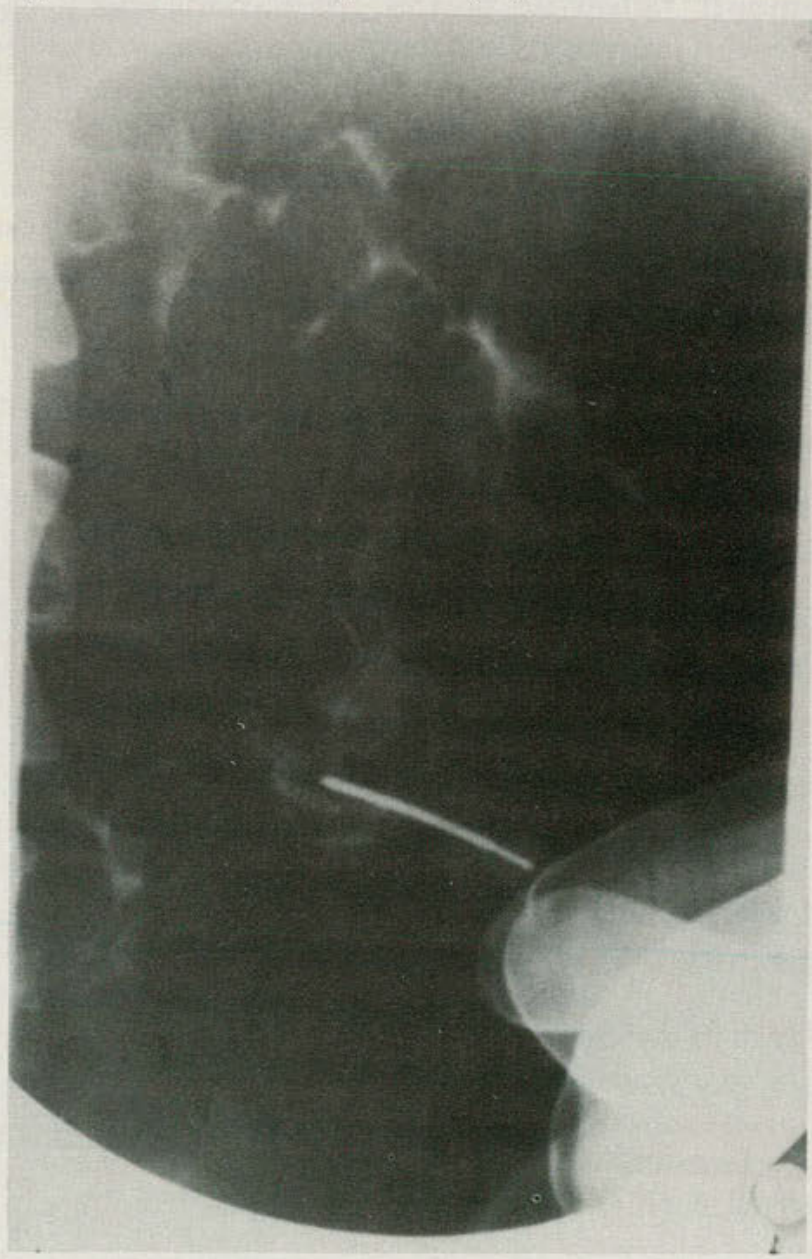




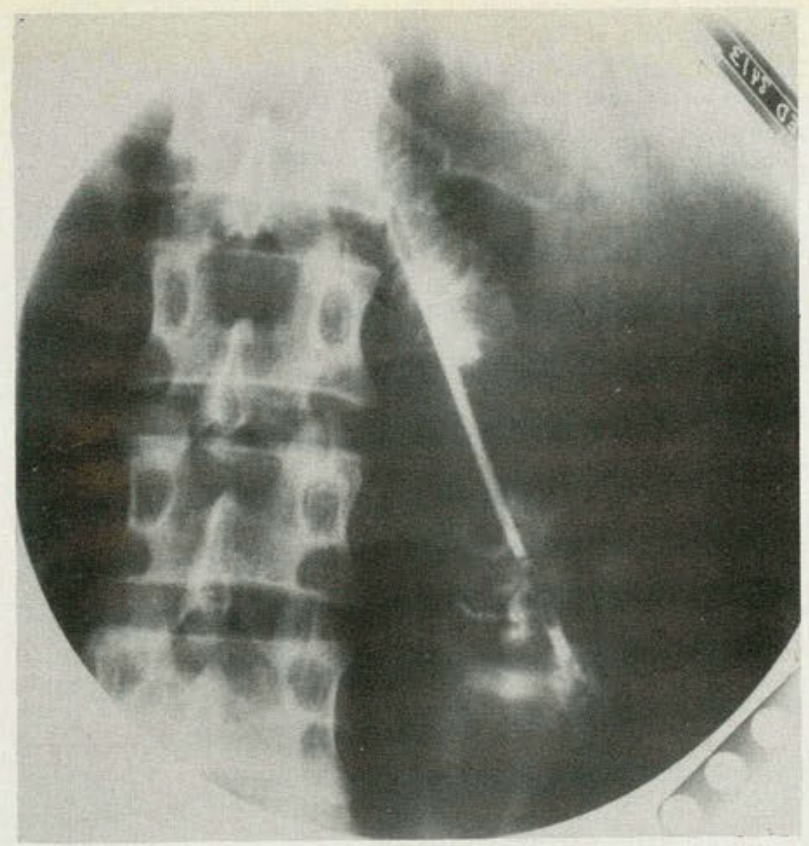

Fig 4. Placement of sheath, with contrast confirmation of afferent limb location.

The procedure was performed with the patient under intravenous sedation. Prophylactic antibiotics were administered just prior to manipulation of the biliary tree and for 24 hours after the procedure.

This case demonstrates that biliary tree access can be achieved safely and on numerous occasions to remove recurrent or retained stones and to dilate biliary strictures. Other investigators ${ }^{14-18}$ also have found these percutaneous techniques for biliary tract access and intervention effective in the management of patients with Oriental cholangiohepatitis, sclerosing cholangitis, and benign biliary strictures.

This subcutaneous Roux limb technique is certainly more feasible than repeated percutaneous transhepatic manipulations of the biliary tree. It also may diminish the need for repeated surgical exploration to manage the complications of this disease, but it would not technically preclude other procedures, including hepatic lobectomy, if required.

\section{Conclusions}

The principles of surgical therapy for Oriental cholangiohepatitis have included stone extraction, external drainage, wide internal drainage, and hepat ic resection in selected cases. Roux-en-Y choled-ochojejunostomy, as described, provides internal drainage as well as ongoing percutaneous access for biliary tract manipulations.

Although further evaluation is required to determine whether the progressive course of Oriental cholangiohepatitis is altered by these interventions, it is our opinion that morbidity from the disease is decreased by regular removal of calculi and dilatation of strictures as they occur.

Fig 5. Passage of floppy wire through the choledochojejunal anastomosis, with contrast confirmation.

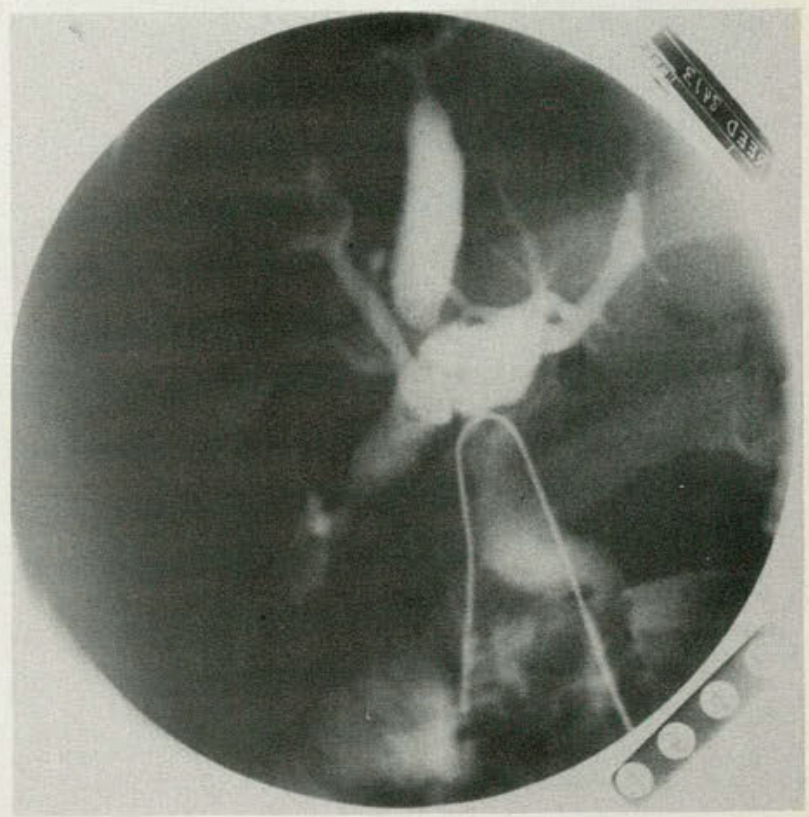

Fig 6. Basket stone extraction of an intrahepatic calculi.

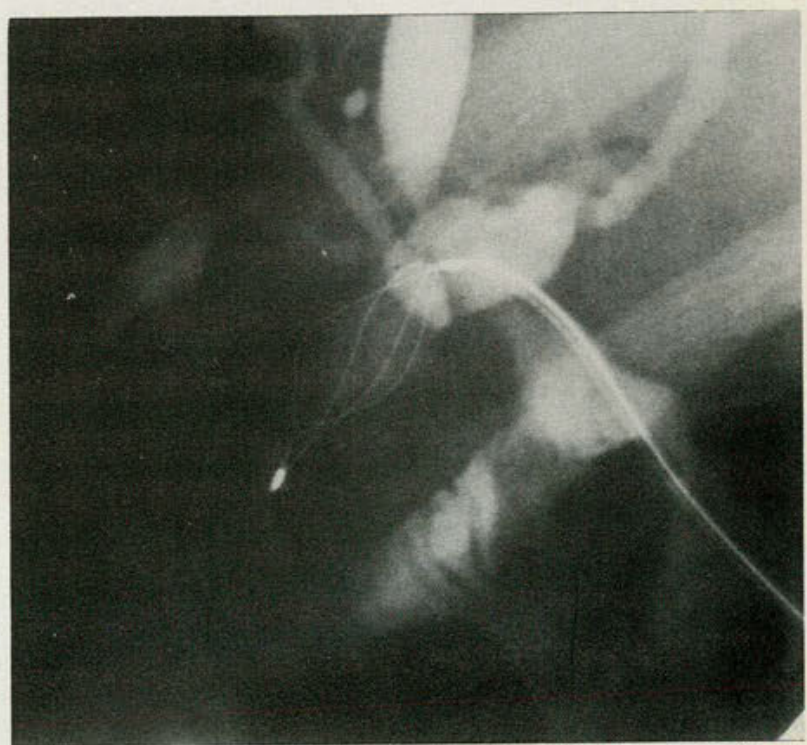




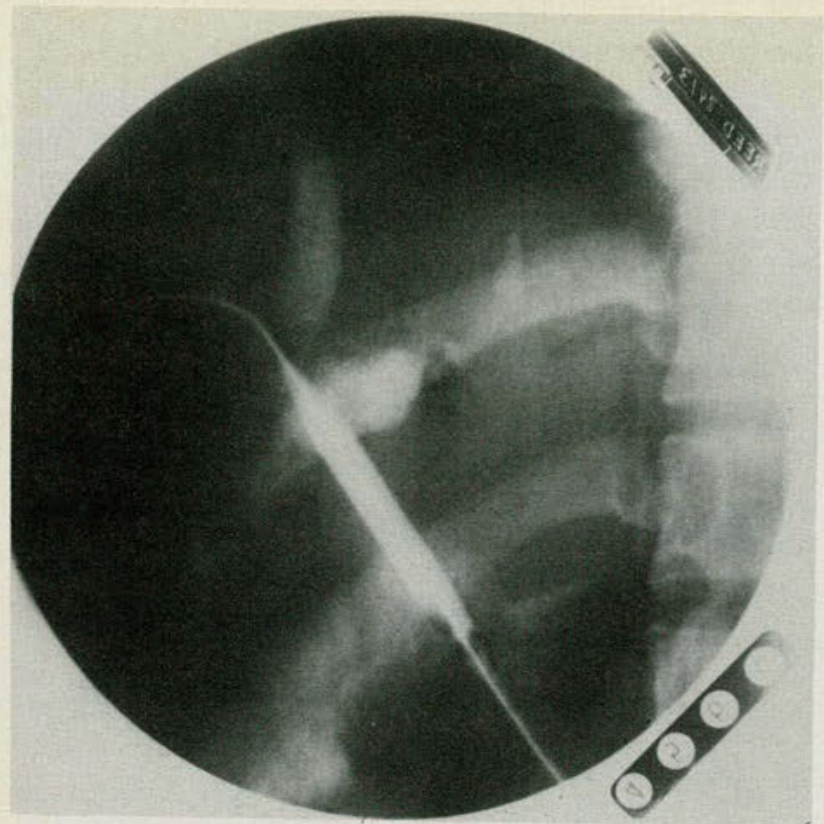

Fig 7. Balloon dilatation of an intrahepatic stricture.

1. Wen C, Lee H: Intrahepatic stones: A clinical study. Ann Surg 1972;175:166-177.

2. Digby KH: Common duct stones of liver origin. Br J Surg 1930;17:578591.

3. Cook J, Hou PC, Ho HC, et al: Recurrent pyogenic cholangitis. $\mathrm{Br} J$ Surg 1954;42:188-203.

4. Stock FE, Fung JHY: Oriental cholangiohepatitis. Arch Surg 1962;84:47-50.

5. Sato T, Matsushiro T, Suzuki N, et al: Results of surgical treatment for intrahepatic gallstones. Tohoku J Exp Med 1977;122:303-312.
6. Maki T, Sato T, Yamaguchi I: Treatment of intrahepatic gallstones. Arch Surg 1964;88:124-134

7. Maki T, Sato T, Matsushiro T: A reappraisal of surgical treatment for intrahepatic gallstone. Ann Surg 1972;175:155-165.

8. Sato T, Suzuki N, Takahashi W, et al: Surgical management of intrahepatic gallstones. Ann Surg 1980;192:28-32.

9. Ti TK: Controversies in biliary drainage for choledocholithiasis and cholangiohepatitis in Singapore. Ann Acad Med Singapore 1981;10:213217.

10. Choi TK, Lim TK, Lam KH, et al: The late result of sphincteroplasty, abstract 6. Proceedings of Pacific Congress of Gastroenterology, 1980, p 186 .

11. Stock FE, Tinckler LF: Choledochojejunostomy in the treatment of cholangiohepatitis. Surg Gynecol Obstet 1955;101:599-606.

12. Ong GB: A study of recurrent pyogenic cholangitis. Arch Surg $1961 ; 84: 199-225$.

13. Hutson DG, Russell E, Schiff E, et al: Balloon dilatation of biliary strictures through a choledochojejuno-cutaneous fistula. Ann Surg $1984 ; 199: 637-647$

14. Kerlan RK Jr, Pogany AC, Goldberg HI, et al: Radiologic intervention in Oriental cholangiohepatitis. AJR 1985;145:809-813.

15. vanSonnenberg E, Casola G, Cubberley DA, et al: Oriental cholangiohepatitis: Diagnostic imaging and interventional management. AJR 1986:146:327-331.

16. Russell E, Yrizarry JM, Huber SJ, et al: Percutaneous transjejunal biliary dilatation: Alternate management for benign strictures. Radiol. ogy 1986;159:209-214.

17. Turner WW Jr, Cramer CR: Recurrent oriental cholangiohepatitis. Surgery 1983;93:397-401.

18. Yellin AE, Donovan AJ: Biliary lithiasis and helminthiasis. Am $J$ Surg 1981;142:128-136.

From the Departments of General Surgery and Radiology, David Grant USAF Medical Center, Travis AFB, Calif 94535-5300. The viewpoints presented in this article are those of the authors and do not necessarily represent the Air Force or Department of Defense.

Reprint requests to Dr Hoefer, Department of General Surgery/ SGHGS, Wilford Hall USAF Medical Center, Lackland AFB, TX 78246-5300. 